\title{
Combined body mass index and abdominal obesity, lifestyle and health in a Norwegian adult population: a cross-sectional study
}

\author{
Inger M. Oellingrath ${ }^{1} \cdot$ Martin V. Svendsen ${ }^{2} \cdot$ Anne K. M. Fell $^{2}$
}

Received: 27 June 2019 / Accepted: 26 March 2020 / Published online: 15 April 2020

(C) The Author(s) 2020

\begin{abstract}
Aim This study aimed to determine the prevalence of combined body mass index and waist circumference (BMI-WC) disease risk categories in a Norwegian adult population aged 18-51 years and describe selected health indicators (lifestyle factors, medical conditions, self-perceived health and high sensitive serum C-reactive protein (hs-CRP)) within these categories.

Subjects and methods A sample of 1318 adults (aged 18-51 years) answered a comprehensive questionnaire covering lifestyle factors, medical conditions, self-perceived health and background variables in the population-based cross-sectional Telemark study, Norway, 2014-2015. BMI, WC and hs-CRP were determined as part of a broader medical examination. Four combined BMI-WC risk categories were constructed, based on recommendations provided by the US National Institutes of Health (NIH), and associations with health indicators examined using multiple logistic regression analyses.

Results More than half of the participants represented combined BMI-WC categories with elevated disease risk $(27 \%$ with increased risk, $11 \%$ with high risk and $19 \%$ with very high risk). Unfavourable health indicators (low physical activity, cardiovascular disease (CVD) history, physician-diagnosed high blood pressure and diabetes, lowered self-perceived health and elevated hs-CRP) increased in line with BMI-WC disease risk. Associations were observed independent of gender, age, education level and residential area.

Conclusion The findings highlight the importance of using both BMI categories and WC for personalised assessment of obesityrelated risk and need for follow-up. The findings are considered relevant to public health intervention programmes targeting adults with overweight and obesity. Follow-up studies are warranted to study morbidity development in the BMI-WC risk categories.
\end{abstract}

Keywords BMI $\cdot$ Waist circumference $\cdot$ Obesity $\cdot$ Lifestyle $\cdot$ Health

\section{Introduction}

Obesity is a well-known risk factor with respect to noncommunicable diseases (NCDs), such as cardiovascular disease (CVD), diabetes and certain types of cancer (World Health Organization, WHO 2014). In Norway, the proportion of adults with obesity has increased substantially since the mid-1990s (Jacobsen and Aars 2015, 2016; Midthjell et al.

Inger M. Oellingrath

inger.m.oellingrath@usn.no

1 Department of Nursing and Health Sciences, Faculty of Health and Social Sciences, University of South-Eastern Norway,

Porsgrunn, Norway

2 Department of Occupational and Environmental Medicine, Telemark Hospital, Skien, Norway
2013), with a marked increase in mean body mass index (BMI; $\mathrm{kg} / \mathrm{m}^{2}$ ) (Jacobsen and Aars 2015; Midthjell et al. 2013) and waist circumference (WC; cm) (Jacobsen and Aars 2016; Midthjell et al. 2013). The increase is evident for both genders, in all age groups and irrespective of socioeconomic differences (Jacobsen and Aars 2015, 2016; Krokstad et al. 2013; Midthjell et al. 2013), and, thus, poses a significant public health problem.

To date, BMI has been the most commonly used anthropometric predictor of overweight, obesity and related disease risk (WHO 2008). However, abdominal obesity as assessed by WC ( $>102 \mathrm{~cm}$ in men and $>88 \mathrm{~cm}$ in women) has been linked to biochemical risk markers, morbidity and all-cause mortality across BMI categories (WHO 2011). Recent studies suggest that assessing the complementarity of BMI categories and WC may have clinical advantages over separate use of BMI and WC to identify health risk (Hou et al. 2013; Yoo et al. 2017). The WHO recommends simultaneous 
measurement of BMI and WC, and suggests joint use to predict disease risk (WHO 2011). In Norwegian studies, BMI and WC have usually been considered separately, with BMI being the most commonly applied measure in research and clinical practice.

The US National Institutes of Health (NIH) has provided a classification of overweight and obesity by BMI, WC and associated disease risks for type 2 diabetes, hypertension and CVD (NIH 2019). Limited knowledge is available regarding the prevalence and characteristics of BMI and WC risk combinations in Norwegian populations. In this paper we use data from the Telemark study, a large population-based study among adults in Telemark county, Norway, to identify combined BMI-WC risk categories, based on the classification provided by the NIH (2019). To characterise these BMI-WC risk categories further, we also report data on selected health indicators, representing lifestyle, relevant medical conditions, subjective health and metabolic disease risk.

The aim of this study was to determine the prevalence of combined BMI-WC disease risk categories in a Norwegian adult population aged 18-51 years and describe selected health indicators (lifestyle factors, medical conditions, selfperceived health and high sensitive serum C-reactive protein (hs-CRP)) within these categories.

\section{Methods}

\section{Study population and design}

The data used were obtained from the cross-sectional part of the Telemark study, a large population-based health survey of adults in Telemark, Norway. The data used in the present paper were obtained from 1318 participants aged 1851 years who attended baseline medical examinations (2014-2015). The participants also completed a comprehensive questionnaire covering lifestyle factors, medical conditions, perceived health and background variables. Complete data for the present purpose were available for 1009 participants. Informed consent was obtained from all individual participants included in the study. Data collection, recruitment methods and characteristics of non-responders in the Telemark study have been described in detail elsewhere (Abrahamsen et al. 2016). The study was conducted in accordance with the guidelines laid down in the Declaration of Helsinki and was approved by the Regional Committees for Medical Research Ethics and the Norwegian Data Protection Authority (REC 2012/1665).

\section{BMI categories}

BMI categories were calculated based on objectively measured height and weight. Cut-off points were chosen in accordance with WHO reference values for adults: underweight < 18.5; normal weight 18.5-24.9; overweight 25 29.9 and obesity $\geq 30$ (WHO 2004). Participants characterised as underweight were excluded from analysis due to small numbers $(n=7)$ and to avoid bias due to other conditions linked to underweight.

\section{Abdominal obesity}

Abdominal obesity was defined as $\mathrm{WC}>102 \mathrm{~cm}$ in men and $>88 \mathrm{~cm}$ in women, indicating substantially increased risk of metabolic complications (WHO 2011). WC was measured at the point of minimal waist or $1 \mathrm{~cm}$ above the navel if this was difficult to detect (Ross et al. 2008; Wang et al. 2003). Participants were divided into two categories using gender-specific cut-off points: abdominal obesity (labelled $\mathrm{WC}_{\mathrm{O}}$ ) and abdominal non-obesity (labelled $\mathrm{WC}_{\mathrm{NO}}$ ), respectively.

\section{Combined BMI and WC disease risk categories}

Four combined BMI-WC categories were constructed. The categories were derived from the combined recommendations of BMI and WC cut-off points made for overweight and obesity and association with disease from the NIH (2019). The combined categories were as follows: (1) BMI normal weight, $\mathrm{WC}_{\mathrm{NO}}$; (2) BMI overweight, $\mathrm{WC}_{\mathrm{NO}}$; (3) $\mathrm{BMI}$ normal or overweight, $\mathrm{WC}_{\mathrm{O}}$; and (4) $\mathrm{BMI}$ obesity, $\mathrm{WC}_{\mathrm{NO}}$ or $\mathrm{WC}_{\mathrm{O}}$. These were labelled 'low risk', 'increased risk', 'high risk' and 'very high risk', respectively. The 'very high risk' category represents an amalgamation of the WHO BMI categories 'obesity class I-III' (WHO 2004) with $\mathrm{WC}_{\mathrm{NO}}$ or $\mathrm{WC}_{\mathrm{O}}$.

\section{Dietary information}

Dietary information was determined by previously validated food and meal frequency questions used in the Oslo Health Study of 2001 (HUBRO) (Norwegian Institute of Public Health (NIPH) 2019). Two distinct eating patterns were identified using principal component analysis (PCA) of the reported dietary responses (Oellingrath et al. 2011). Factor scores for each eating pattern were grouped into categorical variables (tertiles) (Oellingrath et al. 2011). The eating patterns were named 'unhealthy diet' and 'healthy diet', based on the current national recommendations on diet and health (Norwegian Directorate of Health (Helsedirektoratet) 2014) and the ingredients in each pattern. The healthy eating pattern included recommended foods, such as fruits and vegetables, brown bread, fish and fish products, and regular meals, while the unhealthy eating pattern contained energy-rich, low-nutrient foods like biscuits, cakes, sweets, ice cream, processed foods and white bread. 


\section{Physical activity}

Physical activity was assessed through one question reflecting the current daily recommendation for adults $(\geq 30 \mathrm{~min}$ of moderate to vigorous physical activity (MVPA) (Norwegian Directorate of Health (Helsedirektoratet) 2014)): "Are you usually physically active for at least 30 minutes daily?" The answer options were 'Yes' and 'No'.

\section{Smoking}

Smoking habits were divided into three categories: 'current smoker' (daily and occasional smoking combined), 'former smoker' and 'never smoked'.

\section{Medical conditions}

Selected medical conditions, i.e. myocardial infarction, angina pectoris, stroke (cerebrovascular events), physician-diagnosed high blood pressure and diabetes mellitus, were registered using the question (Midthjell et al. 1992): "Do you have or have you ever had any of the diseases/problems?" The answer options were 'Yes' and 'No'. The answers regarding myocardial infarction, angina pectoris and stroke were combined into a single variable, 'CVD history'.

\section{Self-perceived health}

Self-perceived health was assessed using the first question from the short-form health survey (SF-36) (Bowling 2005): "In general, would you say your health is 1 : excellent; 2: very good; 3: good; 4: fair; or 5: poor?" The categories 'excellent' and 'very good' were combined and denoted 'excellent/very good'. The categories 'good', 'fair' and 'poor' were also combined and denoted 'moderate/poor'.

\section{hs-CRP}

hs-CRP was determined from blood samples and analysed as a clinical indicator of low-grade inflammation (Kushner et al. 2010) and metabolic disease risk (Battistoni et al. 2012; Kaptoge et al. 2010; Wang et al. 2013). Venous blood was sampled consecutively and hs-CRP (mg/L) was analysed using the Siemens ADVIA 1800 and according to ISO 15189, at the Department of Medical Biochemistry, Oslo University Hospital, Ullevål, Oslo, Norway. To reflect the lowgrade inflammation threshold, hs-CRP was divided into two categories: $<3 \mathrm{mg} / \mathrm{L}$ and $\geq 3 \mathrm{mg} / \mathrm{L}$ (Kushner et al. 2010).

\section{Background variables}

\section{Age}

All participants were aged 18-51 years and grouped into three categories: '18-31 years', '32-41 years' and ' $42-51$ years'.

\section{Educational level}

This was categorised as follows: 'primary and lower secondary education' (10 years or less), 'upper secondary education' (an additional three to four years) and 'university or university college'.

\section{Residential area}

The area of residence was determined based on registered address. More densely populated coastal areas were labelled 'urban', while less populated inland areas were labelled 'rural'.

\section{Statistical analyses}

Data describing gender differences were analysed using Pearson's $\chi^{2}$ and Fisher's exact test. Multiple logistic regression analysis was used to associate BMI-WC combinations (independent variables) with lifestyle factors (eating patterns, physical activity and smoking), medical conditions, self-perceived health and hs-CRP (dependent variables), adjusting for gender, age, education level and residential area. Odds ratios (ORs) with 95\% confidence intervals (CIs) were calculated for the dependent variables. Only participants with complete data for the main variables $(n=1009)$ were included in the analyses, while missing values for any background variables were included as a separate category. The data were weighted using inverse probability weighting (Seaman and White 2013) to adjust for non-response and sample enrichment in recruitment of persons with asthma for medical examination. Weighting was performed to make the study population representative of the population of Telemark aged 18-51 years with regard to age, gender, residential area and asthma status. For all tests, $p<0.05$ was considered significant, and all the statistical analyses were carried out using SPSS version 23.

\section{Results}

Of the participants, $61 \%$ were women and $39 \%$ were men. Some $37 \%$ of the participants were registered in the highest educational category, 'university/university college', and 37\% in the middle category, 'upper secondary school'. Further 
background characteristics of the sample are specified in Table 1.

More than half of the participants represented combined BMI-WC categories with elevated disease risk (Table 2). Persons with BMI overweight ('increased risk') represented $27 \%$ of the participants, persons with BMI normal weight or overweight combined with abdominal obesity ('high risk') accounted for $11 \%$, while $19 \%$ of the participants were ranked in the category with BMI obesity with or without abdominal obesity ('very high risk').

The gender-specific distribution of BMI, WC and BMIWC risk categories and other health indicators is shown in Table 2. A greater proportion of men than women reported unhealthy eating habits and high blood pressure. Men dominated in the BMI overweight and BMI obesity categories and the BMI-WC 'increased' and 'very high risk' categories, while women dominated in the category with abdominal obesity and the BMI-WC 'high risk' category.

Multiple logistic regression showed that reporting of unfavourable health indicators (low physical activity, CVD history, physician-diagnosed high blood pressure and diabetes, moderate/poor self-perceived health and elevated hsCRP) increased in line with increasing BMI-WC disease risk level (Table 3).

No significant differences in dietary patterns and smoking habits were observed between BMI-WC categories. All associations were observed independently of gender, age, education level and residential area (Table 3).

\section{Discussion}

In this study, we found that more than half of the study population represented combined BMI-WC categories with elevated disease risk based on the NIH's classification (27\% at increased risk, $11 \%$ at high risk and $19 \%$ at very high risk)

Table 1 Population characteristics (unweighted, $n=1009$ )

\begin{tabular}{lc}
\hline & No. $(\%)$ \\
\hline & Age group (years) \\
$18-31$ & $185(18)$ \\
$32-41$ & $277(28)$ \\
$42-51$ & $547(54)$ \\
Education & \\
Primary and lower secondary school & $114(11)$ \\
Upper secondary school & $377(37)$ \\
University/university college & $484(37)$ \\
Other/missing & $34(3)$ \\
Residential area & \\
Urban & $783(78)$ \\
Rural & $226(22)$ \\
\hline
\end{tabular}

(NIH 2019). The likelihood of having other unfavourable health indicators (low physical activity, selected medical conditions, moderate/poor self-perceived health and elevated hsCRP) increased with increasing BMI-WC disease risk level, as indicated by the BMI-WC categories.

In Norway, the BMI and WC distribution curves have shifted towards increased body weight in recent decades and the trend is persistent (Midthjell et al. 2013). Further, there is ongoing discussion of whether 'normal weight' should include the BMI overweight category, and if future health promotion instead should focus on the growing obesity problem. However, persons with BMI overweight are identified as being at increased risk of CVD and other NCDs (Wilson et al. 2002). In our study, the individuals in this 'increased risk' group were four times more likely to report physiciandiagnosed high blood pressure and had almost three times higher likelihood of elevated hs-CRP than those in the reference group. Moreover, many of the individuals in this category may be at risk of developing obesity over time.

Previous studies have related BMI normal weight and overweight in combination with abdominal obesity to higher risk of various metabolic risk indicators, NCDs and mortality (WHO 2011). In our study, participants in the 'high risk' category were five times more likely to report physiciandiagnosed high blood pressure and nine times more likely to report physician-diagnosed diabetes than the reference group, indicating increased disease risk (WHO 2014). Further, the likelihood of elevated hs-CRP was five times higher than in the reference group. Given the current national guidelines limit of $\mathrm{BMI} \geq 30$ for follow-up in primary healthcare (Norwegian Directorate of Health (Helsedirektoratet) 2011), this group with $\mathrm{BMI}<30$ and abdominal obesity may be overlooked and not included in important follow-ups.

Participants who were ranked in the 'very high risk' category were observed to have a substantially increased likelihood of several adverse health indicators. In addition to obesity, they showed a higher probability of low physical activity, had a markedly increased likelihood of all the included medical conditions, elevated hs-CRP and more often reported moderate/poor self-perceived health than persons with lower BMI-WC risk levels. Our results highlight the need for interventions targeted at this growing group of high-risk patients (Jacobsen and Aars 2015, 2016; Midthjell et al. 2013).

The likelihood of achieving the recommended physical activity level was significantly reduced among the 'very high risk' participants. Low physical activity is often associated with obesity, and its causes are complex and related to physical, psychological and external barriers (McIntosh et al. 2016). Nevertheless, promoting physical activity remains important to ensure good health and well-being, and prevention of chronic diseases (Warburton et al. 2006). No clear differences in dietary patterns and smoking were observed between the BMI-WC risk categories. However, one-third of the total 
Table 2 Study population, distribution of main variables (weighted ${ }^{\mathrm{a}}, n=1009$ )

\begin{tabular}{|c|c|c|c|c|}
\hline & No. $(\%)$ & Female & Male & $p$-Value \\
\hline \multicolumn{5}{|l|}{ Body mass index (BMI) categories } \\
\hline Normal weight (NW) & $446(44)$ & $246(52)$ & $200(37)$ & \multirow[t]{3}{*}{$<0.001 * *$} \\
\hline Overweight (OW) & $376(37)$ & $153(32)$ & $223(42)$ & \\
\hline Obesity (OB) & $187(19)$ & $73(16)$ & $114(21)$ & \\
\hline \multicolumn{5}{|l|}{ Waist circumference (WC) categories } \\
\hline WC non-obesity $\left(\mathrm{WC}_{\mathrm{NO}}\right)$ & $730(72)$ & 327 (69) & $403(74)$ & \multirow[t]{2}{*}{$0.041 *$} \\
\hline WC obesity $\left(\mathrm{WC}_{\mathrm{O}}\right)$ & $278(28)$ & $145(31)$ & $133(25)$ & \\
\hline \multicolumn{5}{|l|}{ BMI-WC disease risk categories } \\
\hline Low risk $\left(\mathrm{NW} \mathrm{WC}_{\mathrm{NO}}\right)$ & $433(43)$ & $235(50)$ & $198(37)$ & \multirow[t]{4}{*}{$0.044 * *$} \\
\hline Increased risk $\left(\mathrm{OW} \mathrm{WC}_{\mathrm{NO}}\right)$ & $274(27)$ & $85(18)$ & $189(35)$ & \\
\hline High risk $\left(\mathrm{NW} / \mathrm{OW}, \mathrm{WC}_{\mathrm{O}}\right)$ & $115(11)$ & $79(17)$ & $36(7)$ & \\
\hline Very high risk $\left(\mathrm{OB}, \mathrm{WC}_{\mathrm{NO}}\right.$ or $\left.\mathrm{WC}_{\mathrm{O}}\right)$ & $187(19)$ & $73(16)$ & $114(21)$ & \\
\hline \multicolumn{5}{|l|}{ High intake unhealthy diet } \\
\hline No & $672(67)$ & $335(71)$ & $338(63)$ & \multirow[t]{2}{*}{$0.009 *$} \\
\hline Yes & $337(33)$ & $138(29)$ & 199 (37) & \\
\hline \multicolumn{5}{|l|}{ Low intake healthy diet } \\
\hline No & $673(67)$ & $362(77)$ & $311(58)$ & \multirow[t]{2}{*}{$<0.001 *$} \\
\hline Yes & $336(33)$ & $110(23)$ & $226(42)$ & \\
\hline \multicolumn{5}{|l|}{ Physical activity } \\
\hline As recommended & $675(67)$ & $328(70)$ & $347(65)$ & \multirow[t]{2}{*}{ NS* } \\
\hline Less than recommended & $331(33)$ & $142(30)$ & $189(35)$ & \\
\hline \multicolumn{5}{|l|}{ Smoking } \\
\hline Never & $592(59)$ & $279(59)$ & $313(58)$ & \multirow[t]{3}{*}{ NS** } \\
\hline Former & $221(22)$ & $105(22)$ & $116(22)$ & \\
\hline Current & $197(20)$ & $89(19)$ & $108(20)$ & \\
\hline \multicolumn{5}{|l|}{ CVD history } \\
\hline No & $967(96)$ & 457 (97) & $510(95)$ & \multirow[t]{2}{*}{ NS* } \\
\hline Yes & $42(4)$ & $15(3)$ & $27(5)$ & \\
\hline \multicolumn{5}{|l|}{ High blood pressure } \\
\hline No & $921(91)$ & $448(95)$ & $473(88)$ & \multirow[t]{2}{*}{$<0.001 *$} \\
\hline Yes & $88(9)$ & $24(5)$ & $64(12)$ & \\
\hline \multicolumn{5}{|l|}{ Diabetes } \\
\hline No & $986(98)$ & $465(98)$ & $521(97)$ & \multirow[t]{2}{*}{ NS* } \\
\hline Yes & $24(2)$ & $8(2)$ & $16(3)$ & \\
\hline \multicolumn{5}{|l|}{ Self-perceived health } \\
\hline Excellent/very good & $521(52)$ & $239(51)$ & $282(53)$ & \multirow[t]{2}{*}{ NS* } \\
\hline Moderate/poor & $488(48)$ & $233(49)$ & $255(47)$ & \\
\hline \multicolumn{5}{|l|}{ hs-CRP (mg/L) } \\
\hline$<3.0$ & $824(82)$ & $382(80)$ & $446(83)$ & \multirow[t]{2}{*}{ NS* } \\
\hline$\geq 3.0$ & $184(18)$ & $94(20)$ & $90(17)$ & \\
\hline
\end{tabular}

${ }^{\mathrm{a}}$ Inverse probability weight based on age, gender and area of residence and asthma status

*Fisher's exact test

** Linear by linear

study population reported less physical activity than recommended and $20 \%$ reported current smoking, suggesting a potential for lifestyle changes.

Self-perceived health is a subjective, valuable predictor of general health status (Bowling 2005). Subjects in the 'very high risk' group were more likely to perceive their health as 'moderate/poor', indicating reduced general health among these participants (Bowling 2005). Most of the participants in the intermediate risk categories perceived their health as 'excellent or very good'. This may indicate some discrepancy 
between self-perceived health and actual health risk (Loprinzi 2015). It may be important to raise awareness of actual disease risk associated with overweight and obesity to provide motivation for lifestyle changes among these intermediate risk groups.

A significantly higher likelihood of self-reported diabetes, high blood pressure and CVD history was observed as the BMI-WC risk level increased. In line with previous findings (Yoo et al. 2017), diabetes tended to follow WC obesity, while high blood pressure appeared to be linked more to BMI in our population. Furthermore, the likelihood of having elevated hs-CRP levels increased with combined BMIWC risk level, suggesting an increasing likelihood of lowgrade inflammation (Kushner et al. 2010). Participants in the 'very high' risk group were up to nine times more likely to have elevated hs-CRP than the reference group. Although no causality can be determined from our cross-sectional data, the findings supplement previous studies in which BMI or WC have been associated to hs-CRP levels (Choi et al. 2013). However, any underlying associations between BMI-WC combinations and hs-CRP could be affected by co-morbidity, as hs-CRP-related medical conditions (Battistoni et al. 2012; Kaptoge et al. 2010; Wang et al. 2013) were also reported and increased by increasing the BMI-WC risk level.

Overall, our findings highlight the importance of using BMI categories and WC in combination for personalised assessment of obesity-related risk and need for follow-up. The findings are also considered relevant to public health intervention programmes targeting adults with overweight and obesity.

The strengths of this study are the relative large study sample, objective height and weight measurements for the calculation of BMI and simultaneous measurement of WC. Further advantages are the collection of a range of health information using previously validated questions and the availability of important background variables.

The study also has limitations that should be recognised. Participants' self-reported lifestyle and medical conditions may entail bias due to under-reporting of unhealthy habits and/or over-reporting of healthy habits, or due to errors in recollection. We adjusted for background variables we considered important to BMI, WC and other included health indicators. However, we cannot exclude the possibility that other sociocultural, socio-economic or environmental factors may have attenuated the associations examined. We based our study on the NIH's recommended classification of combined BMI-WC disease risk. However, combinations with abdominal overweight (WC cut-offs $94 / 80 \mathrm{~cm}$ ) may also represent potential increased disease risk (WHO 2011) and should be considered in future studies.

The two categories obesity I and $\mathrm{WC}_{\mathrm{NO}}$ (NIH 2019) were collapsed to the 'very high risk' category due to small num- 
bers $(n=24)$. This may have attenuated the risk level in this category compared to the recommended combinations. However, since there were relatively small numbers in this category and similar results were obtained if they were excluded, we consider this effect to be limited.

Our study population was younger than 51 years of age and only a few participants reported the selected medical conditions, probably because such conditions generally emerge later in life. This may have led to underestimation compared to the general adult population. Further, the data collection was limited to one Norwegian county and the results are, therefore, not necessarily representative of the national population. Finally, due to the study's cross-sectional design, no causal inference may be concluded.

\section{Conclusion}

Our findings provide novel information on the distribution of combined body mass index and waist circumference (BMI-WC) disease risk categories, lifestyle and health among Norwegian adults. More than half of the population represented combined categories associated with elevated disease risk. Unfavourable health indicators increased with increasing disease risk, as indicated by the BMI-WC categories. The findings highlight the importance of using both BMI categories and WC for personalised assessment of obesity-related risk and need for follow-up, and are considered relevant to public health intervention programmes. Follow-up studies are warranted to study morbidity development in the combined BMI-WC risk categories.

Acknowledgements The authors wish to thank Regine Abrahamsen, Geir Klepaker, Gølin Finkenhagen Gundersen and Johan A. Oellingrath for their assistance with the data collection. The authors are grateful to Professor Johny Kongerud for his contribution to the design of the main study. The research was supported by funding from the University of South-Eastern Norway and Telemark Hospital.

Funding information This research received no specific grant from any funding agency in public or commercial sectors. The research was supported by funding from the University of South-Eastern Norway and Telemark Hospital. Open Access funding provided by University Of South-Eastern Norway.

Availability of data and materials The datasets generated and/or analysed during the current study are not publicly available due to individual privacy regulations, but are available from the corresponding author on reasonable request.

\section{Compliance with ethical standards}

Informed consent was obtained from all individual participants included in the study. The study was conducted in accordance with the guidelines laid down in the Declaration of Helsinki and were approved by the Regional Committees for Medical Research Ethics and the Norwegian Data Protection Authority (REC 2012/1665).
Conflict of interest The authors declare that they have no conflict of interest.

Open Access This article is licensed under a Creative Commons Attribution 4.0 International License, which permits use, sharing, adaptation, distribution and reproduction in any medium or format, as long as you give appropriate credit to the original author(s) and the source, provide a link to the Creative Commons licence, and indicate if changes were made. The images or other third party material in this article are included in the article's Creative Commons licence, unless indicated otherwise in a credit line to the material. If material is not included in the article's Creative Commons licence and your intended use is not permitted by statutory regulation or exceeds the permitted use, you will need to obtain permission directly from the copyright holder. To view a copy of this licence, visit http://creativecommons.org/licenses/by/4.0/.

\section{References}

Abrahamsen R, Svendsen MV, Henneberger PK et al (2016) Nonresponse in a cross-sectional study of respiratory health in Norway. BMJ Open 6:e09912. https://doi.org/10.1136/bmjopen-2015009912

Battistoni A, Rubattu S, Volpe M (2012) Circulating biomarkers with preventive, diagnostic and prognostic implications in cardiovascular diseases. Int J Cardiol 157:160-168. https://doi.org/10.1016/j.ijcard. 2011.06.066

Bowling A (2005) Just one question: if one question works, why ask several? J Epidemiol Community Health 59:342-345. https://doi. org/10.1136/jech.2004.021204

Choi J, Joseph L, Pilote L (2013) Obesity and C-reactive protein in various populations: a systematic review and meta-analysis. Obes Rev 14:232-244. https://doi.org/10.1111/obr.12003

Hou X, Lu J, Weng J et al (2013) Impact of waist circumference and body mass index on risk of cardiometabolic disorder and cardiovascular disease in Chinese adults: a national diabetes and metabolic disorders survey. PLoS One 8:e57319. https://doi.org/10.1371/journal. pone.0057319

Jacobsen BK, Aars NA (2015) Changes in body mass index and the prevalence of obesity during 1994-2008: repeated cross-sectional surveys and longitudinal analyses. The Tromsø Study. BMJ Open 5:e007859. https://doi.org/10.1136/bmjopen-2015-007859

Jacobsen BK, Aars NA (2016) Changes in waist circumference and the prevalence of abdominal obesity during 1994-2008 - cross-sectional and longitudinal results from two surveys: the Tromsø study. BMC Obes 3:41. https://doi.org/10.1186/s40608-016-0121-5

Kaptoge S, Di Angelantonio E, Lowe G et al (2010) C-reactive protein concentration and risk of coronary heart disease, stroke, and mortality: an individual participant meta-analysis. Lancet 375:132-140. https://doi.org/10.1016/s0140-6736(09)61717-7

Krokstad S, Ernstsen L, Sund ER et al (2013) Social and spatial patterns of obesity diffusion over three decades in a Norwegian county population: the HUNT Study. BMC Public Health 13:973. https://doi. org/10.1186/1471-2458-13-973

Kushner I, Samols D, Magrey M (2010) A unifying biologic explanation for "high-sensitivity" C-reactive protein and "low-grade" inflammation. Arthritis Care Res 62:442-446. https://doi.org/10.1002/acr. 20052

Loprinzi PD (2015) Factors influencing the disconnect between selfperceived health status and actual health profile: implications for improving self-awareness of health status. Prev Med 73:37-39. https://oi.org/10.1016/j.ypmed.2015.01.002 
McIntosh T, Hunter DJ, Royce S (2016) Barriers to physical activity in obese adults: a rapid evidence assessment. J Res Nurs 21:271-287. https://doi.org/10.1177/17449887116647762

Midthjell K, Holmen J, Bjørndal A, Lund-Larsen G (1992) Is questionnaire information valid in the study of a chronic disease such as diabetes? The Nord-Trøndelag diabetes study. J Epidemiol Community Health 46:537-542

Midthjell K, Lee CM, Langhammer A et al (2013) Trends in overweight and obesity over 22 years in a large adult population: the HUNT Study, Norway. Clin Obes 3:12-20. https://doi.org/10.1111/cob. 12009

National Institutes of Health (NIH) (2019) Classification of overweight and obesity by BMI, waist circumference, and associated disease risks. U.S. Department of Health \& Human Services. https://www. nhlbi.nih.gov/health/educational/lose_wt/BMI/bmi_dis.htm. Accessed 17 Jun 2019

Norwegian Directorate of Health (Helsedirektoratet) (2011) Prevention, identification and treatment of overweight and obesity in adults. National guidelines for primary care services (in Norwegian)

Norwegian Directorate of Health (Helsedirektoratet) (2014) Anbefalinger om kosthold, ernæring og fysisk aktivitet (Norwegian guidelines on diet, nutrition and physical activity) (in Norwegian). https://www. helsedirektoratet.no/rapporter/anbefalinger-om-kosthold-ernaeringog-fysisk-ativitet/Anbefalinger\%20om\%20kosthold\%20ern\%C3\% A6ring\%20og\%20fysisk\%20aktivitet.pdf/_/attachment/inline/ 2 f 5 d 80 b 2 - e 0 f 7 - 4071 - a 2 e $5-3$ b 080 f 99 d 37 d: 2aed64b5b986acd14764b3aa7fba3f3c48547d2d/Anbefalinger\% 20 om $\% 20$ kosthold $\% 20$ ern $\%$ C3\% A6ring\%20og\%20fysisk\% 20aktivitet.pdf. Accessed 14 Apr 2020

Norwegian Institute of Public Health (NIPH) (2019) The Oslo Health Study (HUBRO). https://www.fhi.no/en/more/health-studies/ landsomfattende-helseundersokelser-lhu/helseundersokelser/theoslo-health-study-hubro/. Accessed 14 Apr 2020

Oellingrath IM, Svendsen MV, Brantsæter AL (2011) Tracking of eating patterns and overweight - a follow-up study of Norwegian schoolchildren from middle childhood to early adolescence. Nutri J 10:106
Ross R, Berentzen T, Bradshaw AJ et al (2008) Does the relationship between waist circumference, morbidity and mortality depend on measurement protocol for waist circumference? Obes Rev 9:312325. https://doi.org/10.1111/j.1467-789X.2007.00411.x

Seaman SR, White IR (2013) Review of inverse probability weighting for dealing with missing data. Stat Methods Med Res 22:278-295. https://doi.org/10.1177/0962280210395740

Wang J, Thornton JC, Bari S et al (2003) Comparisons of waist circumferences measured at 4 sites. Am J Clin Nutr 77:379-384. https:// doi.org/10.1093/ajen/77.2.379

Wang X, Bao W, Liu J et al (2013) Inflammatory markers and risk of type 2 diabetes: a systematic review and meta-analysis. Diabetes Care 36: 166-175. https://doi.org/10.2337/dc12-0702

Warburton DER, Nicol CW, Bredin SSD (2006) Health benefits of physical activity: the evidence. Can Med Assoc J 174:801-809

Wilson PW, D'Agostino RB, Sullivan L, Parise H, Kannel WB (2002) Overweight and obesity as determinants of cardiovascular risk: the Framingham experience. Arch Intern Med 162:1867-1872. https:// doi.org/10.1001/archinte.162.16.1867

World Health Organization (WHO) (2004) BMI classification. https:// apps.who.int/bmi/index.jsp?introPage=intro_3.html. Accessed 24 May 2017

World Health Organization (WHO) (2008) Global database on body mass index

World Health Organization (WHO) (2011) Waist circumference and waist-hip ratio. Report of a WHO expert consultation, Geneva, 8 11 December 2008

World Health Organization (WHO) (2014) Global status report on noncommunicable diseases 2014

Yoo B, Nam H, Hwang IC, Park Y (2017) Correlation of cardiovascular risk factors with central obesity and multiple body mass index in Korea. Korean J Fam Med 38:338-345. https://doi.org/10.4082/ kjfm.2017.38.6.338

Publisher's note Springer Nature remains neutral with regard to jurisdictional claims in published maps and institutional affiliations. 